\title{
NARCISSISM AND PHILOSOPHY
}

\author{
by \\ Steven James Bartlett \\ Visiting Scholar in Philosophy and Psychology, Willamette University \\ and \\ Senior Research Professor, Oregon State University \\ Website: http://www.willamette.edu/ sbartlet
}

KEYWORDS: philosophy as narcissism, narcissism in philosophy

This paper was originally published in the Netherlands, in Methodology and Science: Interdisciplinary Journal for the Empirical Study of the Foundations of Science and Their Methodology, Vol. 19, No. 1, 1986, pp. 16-26. Methodology and Science ceased publication in the mid-1990s and all rights to this paper reverted to the author. This electronic version supplements the original text with internet-searchable keywords.

The author has chosen to re-issue this work as a free open access publication under the terms of the Creative Commons Attribution-NonCommercialNoDerivs license, which allows anyone to distribute this work without changes to its content, provided that both the author and the original URL from which this work was obtained are mentioned, that the contents of this work are not used for commercial purposes or profit, and that this work will not be used without the author's or his executor's permission in derivative works (i.e., you may not alter, transform, or build upon this work without such permission). The full legal statement of this license may be found at

http://creativecommons.org/licenses/by-nc-nd/3.0/legalcode

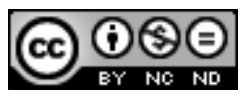

(C) Steven James Bartlett, 2014 


\title{
NARCISSISM AND PHILOSOPHY*
}

\author{
by \\ STEVEN J. BARTLETT \\ Department of Philosophy \\ Saint Louis University \\ Saint Louis, MO 63103, USA
}

\section{Introduction}

The condition we call narcissism began when Nemesis made a handsome youth fall in love with his reflection in a fountain. The lovely maiden Echo was grief-stricken by Narcissus' self-absorption, and gradually pined away until only her voice remained.

Narcissism today is not only a synonym for self-infatuation; it is the name for a clinical psychiatric disorder.

In recent years, psychiatrists and psychotherapists have devoted much attention to narcissism. Patients are being diagnosed in increasing numbers as narcissistic, in part probably because of a heightened sensitivity to the phenomenon.

Narcissism, from a psychological point of view, is an interesting thing. It bears unmistakable similarities to one philosophical position, solipsism. And from a general point of view, as I will try to show, psychological narcissism is descriptive both of certain aspects of personality of many philosophers, and of the nature of many of the positions they propound.

* Two earlier papers examine related topics. One, "Philosophy as Ideology", forthcoming in Metaphilosophy, seeks to study ways in which philosophical positions become self-encapsulating ideologies, and to understand resulting blocks to communication between different philosophical standpoints.

A second paper, "Psychological Underpinnings of Philosophy", attempts to develop a general psychological profile of the predominant philosophical personality.

Psychometrists have demonstrated that members of any profession tend to share identifiable attributes of personality. 


\section{Narcissism Defined}

I want to preface the following observations by saying that the use ! make of psychological categories stems from a desire to encourage psycho. logical self-examination in philosophy. It is unfortunate that many descriptive names for styles of personality have acquired derogatory overtones. This has probably been due to their use by a psychologically distrust ful public, for whom psychotherapeutic concepts are unfamiliar and intimidating. The psychological understanding of narcissism began with an awareness of its central characteristic, self-absorption. We are all narcissists to a degree: If we enjoy our work, our families, our lives, we feel a degree of selfinvolvement which is desirable and healthy. Narcissism becomes of concern to the psychotherapist when the degree of self-absorption of the patient stands in the way of his or her consciousness of the personal needs, intentions, and subjective feelings of others. Extreme narcissism precludes any awareness of this kind; such an individual is unable to see or appreciate the boundaries of others, and so others become mere extensions of self; the separateness of another person is not noted or respected. A narcissist becomes a windowless monad which contains a universe that exists only for it. Similarly, an autistic child is imprisoned by an extreme form of narcissism.

This is the familiar conception of narcissism. Our understanding of the phenomenon has been extended by recent studies in psychiatry; it is my intention here to bring together certain conclusions which they suggest, in an effort to shed light on the psychology of the philosophic enterprise.

Erich Fromm has devoted attention to what he called 'malignant narcissism'.' He characterized this condition in terms of an 'unsubmilted will'. Fromm believed that all healthy adults submit themselves in a variety of ways to something higher than themselves - be it God, truth, love, or another ideal.

Narcissism, he believed, becomes malignant wher an individual's willfulness becomes extreme, when self-involvement reaches a degree that a person is totally uncritical of self and is incapable of responding in a mature

1. The Heart of Man: Its Genius for Good and Evil, New York: Harper and Row, 1964. See also his Anatomy of Human Destructiveness, New York: Holt, Rinehart, and Winston, 1973. 
and constructive way to criticism. When narcissism reaches the stage of malignancy, the individual stands in fear of external criticism because criticism is experienced as an implicit challenge to his or her self-isolation and withdrawal, and, as we will see, threatens the internal dynamics of the narcissist's lonely world of self.

Psychologists since Fromm have identified other defining characteristics of narcissism. Three of these qualities of personality may be grouped together: the need to be always right, pride, and denial of personal fallibility or fault.

It is inherent in the condition of narcissism for an individual to believe that whatever way he or she happens to perceive things is the right way, without the need for further study or reflection. It is typical for the person to resent any attempt to question his or her perceptions; indeed, the usual response is one of surprise followed by indignation and impatience.

The narcissist is keenly sensitive to disagreement, and reacts defensively with an intolerant and overweening pride, which claims a privileged comprehension of exactly how things are.

Clinical narcissism is further characterized by 'scapegoating behavior' - a tendency to blame others and the environment, to construe many things which are beyond personal control as obstacles to the individual's functioning, and to situate responsibility for personal disappointments in the shortcomings of others. The narcissist has a blameful outlook, carries with him or her a record of past pains and bitterness, and will frequently engage in 'finger-pointing', underscoring the culpability of others when there is disagreement or a question of fault.

Prerense is a less easily recognized characteristic of the narcissist. There appears to be a need to camouflage reality, to 'dress up' what may be somewhat colorless or drab, to exaggerate what is already worthy of note, to oppose the common perception, to ignore feelings and to distort them. Psychiatrist M. Scott Peck has devoted a book to a study of this inclination of the narcissist to dissimulate, to lie, about realities of self, others, and world.2

It is this tendency more than any other that makes narcissism difficult to treat in psychotherapy. The narcissist appears to be so caught in a net of

2. M. Scotl Peck, People of the Lie: The Hope for Healing Human Evil, New York: Simon and Schuster, 1983. 
his own fabrications and lies that he has lost, or has given up, the ability to detect his own pretense. The halls of the narcissist are filled with masks: If one mask comes no longer to serve its purpose, there is another to take its place. In the process, the narcissist's sense of identity is dissolved, or rather it is absorbed by the range of masks at his disposal. 'Being true to oneself' ceases, from this perspective, to have any meaning.

The pretense maintained by the narcissist is accompanied by overt pretentiousness: for example, the narcissist will disclaim having hateful feelings or vengeful desires. The narcissist's self-image is one of intrinsic inner perfection and faultlessness.

Under stress, the narcissist will demonstrate a degree of intellectual deviousness that can be quite incredible. Her or she is, as we have noted, uncommitted to any higher principle or authority; hence, there is available a freedom, even a facility, to dodge, to deny, to distort, and to confuse others. This deviousness or slipperiness is interpreted as a desire to avoid direct confrontation or engagement in personal relationships with others; it is an escape, a retreat from honesty.

Deviousness and evasiveness of this kind are associated with schizophrenia: the individual has an impaired ability to 'meta-communicate' - to label accurately the intentions behind the communications and behavior of others. ${ }^{3}$ It is believed that an inability to discriminate on a metacommunicative level leads to a mix-up in the schizophrenic's capacity to distinguish levels of discourse. This is one reason, among others, that schizophrenia is characterized by a kind of disorganization of thought and of expression (appropriately called 'schizophrenic salad'). There seems to be a characteristic resistance to linear, coherent thought and expression, frustrating to a therapist in its almost deliberate-seeming qualities of avoidance and deviousness. 4

Narcissism is further associated with a desire for power: The narcissist is motivated by a need to win, to come ‘ $_{\text {' }}$ on top', if necessary at the expense of others. There is frequently an urge to be in a position of authority. And there is an inclination to treat others as objects, or as mere appendages of

3. See, for example, Gregory Bateson, Steps to an Ecology of Mind, New York: Ballantine Books, 1972, which contains several seminal papers on the theory of schizophrenia.

4. M. Scott Peck, ibid., p. 129n, relates narcissism to 'ambulatory schizophrenia', in which the individual may function successfully in the world, yet exhibits this sort of disorganized thinking when under stress. 
self due to an inability or unwillingness to recognize the boundaries of others - to accept and respect their separateness, the fact that others are persons in their own right. The authority therefore sought by the narcissist is particularly grandiose: it was exhibited by Hitler; it is manifested by nationalistic groups intoxicated by blind ideological self-love. Forms of this same grandiose authoritative style victimize innumerable families in which the personhood of a spouse or of a child is ignored, denied, abused, and perhaps eventually undercut.

The last characteristic of narcissism 1 will mention here is a kind of psychological laziness. The narcissist appears to feel it just is too much trouble and work to become involved in self-examination. A narcissistic mother or father will usually refuse to enter family therapy. To do so compromises the narcissist's unsubmitted will, his or her need for control, power, authority. Therapy is fundamentally a process in which individuals are encouraged to dispense with masks; the narcissist feels that submitting his or her will to the authority of a therapist would be a form of personal suicide. To recapitulate, pathological narcissism is characterized by:

- self-absorption to a degree that walls the individual off from himself, others, and the world;

-. a refusal to submit one's will to a higher principle or to the authority of another; hence, a lendency to react with pronounced defensiveness to criticism;

- a need to be always right, coupled with a sense of comparative personal faultlessness displayed in a prideful, arrogant way;

- scapegoating behavior: the inability to accept that one is sometimes in error, and hence a noticeable pattern of blaming others and situations for personal disappointments, along with a habit of self-consciously keeping a record of past injuries;

- the maintenance of pretense: a compulsion to wear masks, to dissimulate, and to believe in one's actual perfection;

- intellectual deviousness, displayed especially when under stress, and taking the form of ingenious dodging, denials, distortions, and a resulting ability to 'throw up so much dust' that others become confused;

- a 'white-knuckled need' always to be in control; an urge to exercise power and authority over others; and

- a lype of psychological laziness to engage in self-examination; resistance to real selfquestioning.

\section{Causes of Narcissism}

Before going on to relate the preceding discussion of narcissism to philosophy, it is natural to want to ask how narcissism comes about. For many of us, it is incredible that such a psychological condition is possible, that it is possible for individuals to become so tragically cut off from others and 
from themselves, and for this to occur in such a manner that a person becomes incapable or unwilling to admit that this is so.

As yet, clinical narcissism has not been studied extensively or in depth; much remains unknown about the condition, and its genesis.

There are several hypotheses which have so far been suggested: that narcissism is caused by the impact of a childhood trauma which drives a child to build rigid fortifications to protect against further pain. Habits become engrained, and the complex defenses that may have served a child's needs are never given up.

There is also the hypothesis that narcissism comes about in reaction to, or in subjugation to, the unreality of a 'schizophrenogenic' parent. The child attempts to insulate himself from the parent's confused and conflicting messages, draws in, and walls himself off in a world of his own.

Some psychologists have suggested that narcissism may be transmitted: a narcissistic parent's self-absorption blocks the expression of love and security needed by a child who, as a consequence, turns inward and develops patterns of thought and behavior that characterize narcissism.

In all these hypotheses fear plays a central role in maintaining the condition of narcissism. Behind the pretense, the dissimulations, the maskwearing, the denials, the exaggerations, the blaming, deviousness, hunger for control and infallibility, willfulness and resistance to self-questioning - behind these run-away habits that have taken over the personality, lies fear: fear of reality, fear of truth about oneself and one's fallibility, fear of the separateness of others, fear of past events and suffering - fears we all have, but not to the heightened degree of the narcissist. Fears perpetuate the condition; they stand in the way of its acceptance and treatment. The narcissist is fundamentally a victim of his own fears, which seem so terrible and overwhelming they cannot even be thought of; he is lost in an unrecognized labyrinth of his own unacknowledged fashioning.

\section{Narcissism and Philosophy}

Philosophers, like other people, are subject to human frailties. Some are probably clinical narcissists. I do not know if a larger proportion of philosophers is narcissistic than are theologians, poets, composers, artists, or writers. But probably, for reasons I will try to make clear, a greater proportion of the philosophical population suffers from characteristics of 
unacknowledged narcissism than do, for example, scientists.

I believe that the nature of philosophic activity promotes and is encouraged by many qualities of personality which closely resemble qualities that define narcissism. Since I am a philosopher, I am especially concerned with the philosophic profession and its future prospects. I suspect that some of the points I make are true of other professions in which individual expression is encouraged, or in which a system of belief is made a central focus, as in religion or political ideology. However, I want to limit what I have to say here to a discipline in which I have worked for a long time.

\section{Resistance to a unitary, evaluative framework}

In spite of occasional attempts during philosophy's long history to develop a unitary, evaluative methodology, the practice of most philosophy has opposed this objective. Divergent philosophical positions are propounded; there is no shared universe of discourse in which to assess competing views. Indeed, there is no consensus among philosophers as to the desirability of reaching agreement. The activity of philosophers is itself evidence of a resistance to establishing universal criteria of philosophical evaluation; the possibility of such criteria is raised as a philosophical question from the standpoints of competing, specialized positions. The world of philosophical reflection ultimately therefore turns into a monadology.

I submit that this tradition has not come about by accident. After thinking about this for more than two decades, with care and whatever impartiality I have been able to acquire, I have come to suspect that much of philosophy's history reveals the phenomenon of an unsubmitted will which we encountered in our examination of narcissism. Resistance to standards of external evaluation, a desire for freedom from unitary methodological constraints - these are expressions of a willfulness that rebels against submission to a higher discipline, authority, rules of arbitration, or principles of progressive construction.

There are two things involved: the profession of philosophy, with a tradition, momentum, and indeed a will of its own, and individual philosophers, who come and go, transient contributors to historical succession. The nature of the field exerts an attraction upon men and women who, to varying degrees, share certain psychological characteristics. Certainly, if 
philosophy gives approval to an unsubmitted will, the profession is likely to attract individuals who seek the freedom from methodological constraint it offers. It would then be predictable that many individual philosophers will display subjective willfulness, a will that refuses to submit to a higher authority.

The work of science, in contrast, is inspired by a willingness to submit to criteria of evaluation with which any investigator's efforts may be judged. Science is the enemy of intellectual narcissism, for it countenances no private privilege, and accords positive judgment only when consensus of the scientific community is reached.

The occasionally expressed desire that philosophy become scientific is no more nor less than a recommendation that it submit its willfulness to agreed-upon, unitary tenets of reason.

\section{Uncritical self-acceptance}

Paul Arthur Schilpp, Editor of the Library of Living Philosophers, observed that only once in his long editorship, which brought him into close contact with many well-known philosophers, did he meet a philosopher who acknowledged having made a mistake.

Philosophers seem 'possessed' by a need to be always right. They attempt dialogue, but as Henry W. Johnstone, Jr., has noted, what normally ensues are soliloquies in which each appears to own faultless judgment. Philosophical positions pass each other like ships in the night. Philosophers, Schilpp once remarked, 5 do not want to understand one another.

Criticisms of a philosopher's publicly read paper tend to reveal more of a desire for one-upmanship than for constructive communication. Husserl noted that, at philosophy congresses, "philosophers meet but, unfortunately, not the philosophies. The philosophies lack the unity of a mental space in which they might exist for and act on one another."6

Perhaps Husserl was overly sanguine: perhaps neither the philosophies nor the philosophers actually meet. Schilpp and Johnstone seem to have reached this conclusion.

5. In a talk for the Department of Philosophy, Saint Louis University, in September, 1980.

6. Edmund Husserl, "Philosophy as Rigorous Science", translated by Quentin Lauer in Phenomenology and the Crisis of Philosophy, New York: Harper and Row, 1965, p. 5. 


\section{Contentiousness}

The dynamics, the life blood, of philosophical position-taking is contention. Contention is a two-pronged strategy: its objective is to show that one is right, and that the other man is wrong. Philosophers, if they cannot accomplish both, try at least to do one of these. Philosophical argument tends to oscillate between self-demonstration and undermining the opposition. From this point of view, it has long been recognized that training in philosophical argumentation can be useful background for law students. In philosophical contention, the effort to undermine one's opposition is an expression of a kind of scapegoating behavior: destructive criticism is finger-pointing in which blame is ascribed. Philosophical contention seems fundamentally to be motivated by a desire for power. It is a motivation that is now called 'win-no-lose'.

\section{The Pretense}

Philosophy traditionally has espoused Socrates' dictum, 'Know thyself'. However, like people in any age, Athenians of his time, or men and women of the present, there are many things we prefer not to hear, and many things we say which are less than true.

The impulse to do philosophy is the search for truth. Philosophy is not a cafeteria offering a variety of positions from which we may choose to fit our prejudices and belief-systems. (Although one may get this impression after years of teaching freshmen and sophomores, and observing how it is that they come to adhere to a particular philosophic approach.) In any pretense, there is the requirement that one maintain ignorance of the existence of the dissimulation, and that one become invested in it.

If much philosophic activity claims to be a search for truth, but is motivated by a narcissistic interest in building a conceptual home for intuitively accepted beliefs and biases, then its practitioners are involved in pretending.

\section{Intellectual deviousness}

It is impossible in the practice of therapy to force the recognition of pretense. An endless array of masks is available to the committed narcissist. As we have remarked, the position-taking of the narcissist can be so 'slippery', shifting, evasive, or productive of confusion, that pretense becomes 
inpermeable. The condition of narcissism is inspired by perhaps an outgrown, but not discarded, need for self-defense.

Unlike psychological narcissism, philosophical positions do not haveavailable an endless corridor of pretense, nor do they wish it. A philosophical position has an identity: a propounder of that position is committed to certain claims, which are held constant.

Nonetheless, many philosophical positions function in practice so as to evade criticism. They do this by means of terminological or ideational obscurity, a thick smoke-screen in which only initiates can navigate confidently. They do this by means of vagueness, which serves as a shelter when the going gets rough, and by means of rhetorical deftness.

Together, these devices can resist a critical onslaught for a long time, certainly for the duration of a paper's public reading, and sometimes for centuries.

\section{Intellectual lassitude}

Intellectual lassitude finds its way into philosophical position-taking in subtle ways. 7 For purposes here, it is sufficient to consider that philosophical narcissism - for this is the phenomenon I have in view - is a highly effective intellectual system of defenses. It has, in a multitude of instances in the history of the discipline, demonstrated its strength: Philosophical positions are, as a result, I propose, effectively resistant to change. It is a tribute to their genius and to their indomitable narcissism that we are still able to discuss seriously Plato's Theory of Forms and St. Thomas' anima, while we become, pleasantly or frustratingly, lost in Heidegger's vocabulary, or devote years to clawing a way through Husserl's conceptual jungle. Because the dynamics of narcissism works so well, there can be no felt pressures to encourage change.

And so, as we have seen, one of the characteristics of psychological narcissism is a kind of laziness - an inertial resistance to self-examination which, if psychologists are correct, serves to mask fear.

The challenge to change, to 'grow up', to place pretense to one side and move into reality - these are easily expressed, but difficult, sometimes impossible, to accomplish in therapy when narcissism is involved.

7. This phenomenon is discussed more fully in "Psychological Underpinnings of Philosophy" (to appear). 
Perhaps all disciplines, like individuals, must go through an early phase of infantile narcissism. But if this initial phase becomes an epoch, direct confrontation of the pretense is the approach recommended in therapy. 8 And yet, it must be admitted, this works but seldom.

Jung has said that evil arises out of a failure to acknowledge it. Fromm believed that narcissism and evil are linked. Peck suggests that the pretense of narcissism is its cause and its expression, and that pretense, the tendency to lie, convincingly, to oneself and others, is at the root of human evil. Evil is, Peck maintains in the tradition of Christian thinkers, anti-life. Narcissism is anti-growth; it stands in the way of constructive change, of development, of the natural succession of better adaptations which replace earlier ones.

Philosophia perennis may be less a thing to admire than an admission of arrested growth.

\section{Conclusion}

If some of the observations I have proposed correspond to facts about the profession, they need to be discussed openly. On the one hand, it is certainly possible to argue that, in a world becoming increasingly obsessive about technologies, quantification, rules, and methods, philosophy, along with other liberal fields, affords a needed respite. And yet, on the other hand, one may wonder: If philosophy and its practitioners are caught in a mad, i.e., unrecognized, self-destructive circle perpetuated by the spirit of narcissism, we can break free only if we will face the reality squarely, acknowledging our fears, but refusing to give them sway over us. If to a significant degree philosophy is an incarnation of a kind of narcissism, then, in the courage we summon to admit this, the blind habits of narcissism will gradually lose their power over us.

Dr. Bartletl was born in Mexico and received his Ph.D. from the Universite de Paris. He has taught at the University of Florida, the University of Hartford, and was Professor of Philosophy at Saint Louis University until 1984, when he left teaching to devote himself full-time io research and writing. He has published five books and monographs and more than thirty papers in professional journals. Dr. Bartlett is currently working on a book, a guide to psychotherapy. 